\title{
OS OUTROS, QUEM SOMOS? FORMAÇÃO DE PROFESSORES INDÍGENAS E IDENTIDADES INTERCULTURAIS
}

\author{
NIETTA LINDENBERG MONTE \\ Comissão Pró-Índio do Acre*
}

\section{RESUMO}

O trabalho pretende fornecer subsídios críticos à educação escolar indígena no Brasil, centrando-se no aprofundamento do tema do currículo intercultural e a formação de professores indígenas. Para isso, contextualiza a história de projetos de responsabilidade de organizações não governamentais dedicadas, no Brasil nos finais do século XX, à construção de propostas curriculares para o magistério e as escolas indígenas, com visivel repercussão nas políticas públicas oficiais. Aborda especialmente alguns desafios teórico-metodológicos que nesses processos estão sendo enfrentados pelos educadores não índios ao desenharem e desenvolverem os currículos interculturais, com suas inevitáveis implicações sobre a representação das identidades sociais e o uso das línguas indígenas e do português de professores e de alunos indígenas.

FORMAÇÃO DE PROFESSORES - INNDIOS - CURRÍCULOS - INTERCULTURAL

\begin{abstract}
THE OTHERS, WHO WE ARE? TRAINING INDIGENOUS TEACHERS AND INTERCULTURAL IDENTITIES. The paper intends to give critical information about the indigenous education in Brazil, with its focus to the subject of intercultural curriculum and the Indians Teachers Training Courses. For that, it describes the history of some projects under the responsibility of non governmental organisations that were working, by the end of the XX century, for the construction of the Indians Curriculum, with visible repercussion in the actual official public politics. It approaches, specially, theoretical and methodological challenges that spring about for the non-indian educators in these processes, concerning the curriculum planing and development, along with the unavoidable implications over the social identities representations of the indians teachers and their students, and the use of Indians and Portuguese Languages.
\end{abstract}

O artigo, sob o título "O Currículo Intercultural, alguns textos possíveis", foi apresentado pela autora no Simpósio El reto de la educación intercultural (y bilingüe) en el siglo XXI. ¿Como hacerla desde la perspectiva del usuario?, durante o 50 Congresso Internacional de Americanistas na Universidade de Varsóvia, Polônia, em julho de 2000, e foi reformulado para esta edição.

* A Comissão Pró-Índio do Acre é uma entidade da sociedade civil de assessoria às sociedades indígenas do Acre e sudoeste do Amazonas em programas de educação, saúde e meio ambiente, das mais antigas organizações não governamentais brasileiras, com 22 anos de vida institucional. 
Sem dúvida, a mudança educativa em uma sociedade precisa reverter o fracasso financeiro, institucional e científico da escola (Bayet, citado em Lesourne 1993) mediante um trabalhoso e frágil processo de abertura e negociações políticas, um amplíssimo contexto de participação, muitas investigações diagnósticas, oferta coerente de formação docente, novos materiais didáticos, novas propostas curriculares e estratégias eficientes para desencadear as mudanças.

Munoz, 1998, p. 37, tradução nossa

\section{APRESENTANDO CERTOS FATOS}

A relevância de alguns grupos organizados da sociedade civil na formulação das políticas de educação escolar indígena vem sendo motivo de cantada conquista no Brasil das últimas décadas. Diferentes atores políticos envolvidos com a implementação da nova escola indígena - organizações não governamentais, movimentos indígenas e órgãos de Estado -, de diversas posições e perspectivas políticas, pronunciam discursos similares sobre a educação requerida. É como se as vozes das sociedades indígenas, há séculos silenciadas pelas políticas educacionais, finalmente pudessem formular e explicitar seu projeto de escola, fazê-lo ecoar e reproduzir, ainda que sob intenso debate e conflito, em forma de novas propostas de políticas públicas a serem desenvolvidas pelo Estado brasileiro.

Em 1991, o Ministério de Educação e Desporto - MEC - passa a responder pela complexa coordenação das novas ações educacionais para indígenas, dentro do corpo maior da educação para todos os brasileiros. (Tal tarefa estivera nos últimos 30 anos circunscrita e protegida por um organismo específico de porte federal, a Fundação Nacional do Índio - Funai.) Desde então, com seu dever de assegurar direitos constitucionais e influenciar as políticas descentralizadas nos estados e municípios, o MEC passa a apresentar, às 23 secretarias de educação nos estados brasileiros com população indígena, algumas dessas experiências exemplares e referenciais produzidas pela sociedade. Convocam-se, assim, as secretarias a atuar de acordo com determinadas linhas de ação educacional, aproveitando-se de alguns conceitos e metodologias já explicitados em documentos não oficiais por organizações civis, tornando-os conhecidos e legitimados. Incentivam-se, enfim, os novos executores de políticas estaduais e municipais, dirigidas às quase duas centenas de sociedades indígenas do país, a reconhecer o vazio financeiro, técnico e humano para dar rumo a essas novas formas de políticas educacionais e a inspirarem-se nos reflexos positivos extraídos dos referidos exemplos:

Até muito recentemente, as principais e mais bem-sucedidas experiências de formação de professores indígenas em desenvolvimento no Brasil foram iniciativas de 
entidades de apoio aos índios. Consideradas alternativas, vêm obtendo gradativamente reconhecimento legal. Diante do vazio propositivo das agências governamentais, estas iniciativas de caráter local tornaram-se referência para a conceituação e implementação de uma política pública de educação escolar indígena, voltada a atender a demanda de escolarização das comunidades indígenas, a partir de um paradigma da especificidade, da diferença, da interculturalidade e da valorização da diversidade lingüística. (Brasil, 1999)

Como exemplo das idéias e dos ideais formulados e difundidos aos estados como diretrizes e parâmetros pelo $\mathrm{MEC}^{\prime}$, especificamente políticos, mencionamse projetos de educação com longa trajetória, estilo próprio, elaborados na Amazônia legal brasileira, que hoje disseminam-se de norte a sul, e comportam práticas políticas heterogêneas ${ }^{2}$. São iniciativas não governamentais e são citadas como fontes de inspiração para o poder público e para o campo jurídico (Lei de Diretrizes e Bases - LDB -, 1996; Plano Nacional de Educação - PNE -, I 998; Referencial Curricular Nacional Para Escolas Indígenas - RCNEI -, I998; Resolução do Conselho Nacional de Educação - CNE -, 1999) para fundamentar seu próprio discurso e, com maior dificuldade, suas práticas institucionais e políticas.

\section{BUSCANDO PONTOS DE CONTATO}

Que características gerais podem ser atribuídas a essas experiências e projetos? Será que as ações pedagógicas e institucionais desenvolvidas nesses casos,

I. O Ministério da Educação vem produzindo, por meio de uma equipe de consultores, fora dos quadros técnicos internos desse órgão, vários documentos de ordem formativa, mais como subsídio do que norma. Entre eles, estão as Diretrizes Nacionais para a Educação Escolar Indígena (Brasil, 1993) preparado pelos membros do Comitê Nacional de Educação Indígena. Um documento de maior fôlego técnico e político, o Referencial Curricular Nacional para Escolas Indígenas (Brasil, 1998) foi elaborado com a participação de amplos setores e atores institucionais - universidades, organizações civis, especialistas indígenas. Estabeleciam-se, por meio dele, os fundamentos comuns das ações específicas a serem desenvolvidas em cada caso. No ano 2000, o MEC se propôs a preparar mais um documento orientador, destinado às políticas de formação de professores, com intenção de promover, no processo de elaboração técnica, a participação e o consenso entre os setores sociais envolvidos.

2. Exemplificam-se esses processos pela atuação das organizações indígenas, como a Comissão dos Professores Indígenas do Amazonas, Roraima e Acre - Copiar -, a Organização Geral dos Professores Tikuna - OGPTB - no Estado do Amazonas, a Federação dos Organizações Indígenas do Rio Negro - FOIRN -, as entidades de apoio, Comissão Pró-Índio do Acre CPI/AC -, o Centro de Trabalho Indigenista - CTI -, o Instituto Socioambiental - ISA -, o Instituto de Antropologia e Meio Ambiente - IAMA -, o Conselho Indigenista Missionário Cimi -, a Operação Anchieta, além de alguns outros. 
no que tiveram e têm de acertadas naqueles contextos históricos particulares, podem ser transferidas às políticas das secretarias de educação em geral, com seu alto grau de hierarquia e tradição burocrática? Haverá, por outro lado, nesses projetos alternativos algumas características comuns e replicáveis, pelo seu grau de generalidade e eficácia, para outras realidades que estejam experimentando processos similares ainda que não idênticos?

Meu esforço é aqui trazer elementos para a discussão de algumas questões que atordoam tanto os que querem contribuir para uma teoria da educação escolar indígena (saindo do plano dos fragmentos de realidades contextuais) como os planificadores das políticas (incidindo sobre a melhoria dessas realidades, quase sempre carentes e conflituosas). Uma das questões que se colocam nesse contexto diz respeito à possível identificação de traços gerais, do ponto de vista educacional e institucional, que sirvam como subsídio aos educadores e técnicos envolvidos com a grande tarefa pública atual de formação dos professores para as escolas indígenas.

Ou seja, trata-se de pensar o que é possível resgatar dessas experiências pioneiras, para que as instituições que hoje atuam no desencadeamento das políticas estaduais e dos programas públicos de formação de professores indígenas, nos novos contextos da história brasileira, possam aproveitar-se delas.

Apresento, para isso, alguns dados históricos extraídos de minha própria história como educadora dedicada profissionalmente à formação de professores indígenas, entendendo esses dados pessoais como parte da história das políticas educacionais contemporâneas para indígenas no Brasil. Vou proceder a um retrato $3 \times 4$ de uma determinada experiência educacional, o projeto Uma Experiência de Autoria, desenvolvido pela organização não governamental brasileira Comissão Pró-Índio do Acre - CPI/AC -, à qual pertenço, sendo, inclusive, uma de suas fundadoras e coordenadora pedagógica desde 1983. Ao mesmo tempo, busco demonstrar alguns dos elementos que se foram constituindo, ao longo dos anos, no eixo comum dos cursos de formação de professores indígenas no Brasil, aproximando os fios da história de alguns outros projetos de responsabilidade de organizações civis. Tento extrair dessa relação idéias que registrem e ilustrem uma parte das nossas práticas políticas e educacionais e tragam os fios que ligam uma experiência particular a outras práticas e políticas, em outras paisagens regionais e em cenários de outros atores. $\bigcirc$ sentido é contribuir para ampliarmos o entendimento do que cada um de nós faz em seu campo particular e único, a partir de possibilidades comparativas e de estudos de casos, auxiliando outros professores e planejadores de políticas educacionais a avaliar e a reanimar suas próprias práticas, sempre inter-relacionadas por alguns princípios compatíveis e histórias similares. 
Parte integrante de uma rede de programas educacionais civis para populações indígenas no Brasil dos últimos 20 anos, a CPI/AC tem sido reconhecida por seus pares como responsável por formular uma das primeiras propostas curriculares alternativas às vigentes nas escolas rurais e urbanas, que respeita as orientações culturais e lingüísticas das sociedades indígenas participantes. Buscou-se firmar, na prática, antes mesmo de estabelecidos novos marcos constitucionais no país, o direito a uma educação bilíngüe e intercultural (conceitos já presentes nos ideais da Educação Intercultural e Bilíngüe - EIB - em toda a América Latina), agregando também os princípios de sua "especificidade e diferença", de forma a garantir a flexibilidade própria à pluralidade das sociedades indígenas que vivem no Brasil.

Alternativo ao Estado, o projeto conquistou o reconhecimento e a possibilidade de integrar-se ao sistema de ensino público, pela incorporação dos professores e suas escolas na rede estadual, tendo sido, entretanto, assegurada a sua autonomia curricular e administrativa. Abriu interessante jurisprudência para a flexibilização e a regulamentação dos currículos indígenas pelos Conselhos Estaduais de Educação dos estados brasileiros, tornando-se referencial político e educacional no Acre e em outros estados.

\section{OS DIREITOS INDÍGENAS E OS CURRÍCULOS ESCOLARES}

De que maneira tais acontecimentos estiveram inseridos no contexto nacional e puderam configurar parte das chamadas lutas sociais do final do século $X X$ ? Pensando aproximar-me da questão, apresento alguns dados históricos adicionais da formação do campo atual das idéias e das leis sobre a educação escolar indígena no Brasil.

No período ainda nebuloso das ditaduras latino-americanas, pequena rede de organizações não governamentais passam não só a existir, mas a desenvolver ações de apoio às sociedades indígenas, sobretudo no norte e centro-oeste do país. Contribuem para a tomada de consciência dos direitos indígenas e para a instalação de uma política pública dirigida a essas sociedades, até então desconsideradas em suas particularidades antropológicas e jurídicas. Direitos em relação à posse e ao usufruto das terras que imemorialmente habitam, às melhores condições de vida, à educação e à saúde e ao exercício da diversidade no seio da comunidade nacional.

Nesse contexto, algumas experiências educativas são desenvolvidas em escala local com algumas etnias ou com um conjunto delas. Dizem respeito ao novo campo de serviços sociais prestados pelos jovens profissionais das Organizações 
Não Governamentais - ONGs - nascentes, especialmente no campo das lutas territoriais ${ }^{3}$. São também iniciadas, nesse período, a organização de cooperativas de produção e consumo para a comercialização da borracha e outros produtos da floresta, enfrentando-se a complexidade política e econômica das questões do mercado extrativista, e a luta com os patrões dos seringais estabelecidos na Amazônia. As experiências de apoio a essas frentes de trabalho, embora específicas nas várias partes do país, são acompanhadas por atividades de cunho educativo que passam a ser desenvolvidas por essas entidades. Em seus primórdios, consistiam na alfabetização de jovens das comunidades indígenas locais, para finalidades de caráter político e cultural, relacionadas ao reordenamento positivo de relações com a sociedade nacional e regional e à valorização da língua e da cultura. Eram promovidas nessa época por antropólogos, indigenistas e os novos missionários oriundos da teologia da libertação, engajados nas lutas pelos direitos sociais, na esteira já lançada em escala mais ampla pela "pedagogia do oprimido" de Paulo Freire e pela nascente educação popular.

Tais experimentos vão ganhando força como ações institucionais, ampliando sua equipe de profissionais, deslocando-se o foco da antropologia para o ensino e para a formação de professores. Começa a se disseminar no país uma tradição de projetos de educação escolar indígena promovidos por ONGs, com apoio técnico de especialistas de algumas universidades, além do apoio de organizações humanitárias internacionais, com significativa repercussão entre as sociedades indígenas mais organizadas pelo contato. Passa-se a exigir também que essas iniciativas ampliem seu campo de ação, transformando seus objetivos de caráter pontual em programas a médio prazo, gradualmente adotados e ampliados como políticas de Estado. Seu centro de atenção é a formação de professores indígenas em cursos presenciais anuais na cidade e em ações de pesquisa e ensino nas aldeias ao longo dos anos. Tal meta é realizada por um conjunto de ações específicas de nível técnico, entre as quais a elaboração de materiais didáticos por parte dos próprios professores indígenas nas diversas línguas e em português, atendendo-se à necessidade de renovação curricular nas diversas áreas de conhecimento. Também são imprescindíveis as viagens de acompanhamento e apoio pedagógico pela equipe do setor de educação a todas as escolas em fase de implantação, com a finalidade

3. Alguns antropólogos dedicados às pesquisas e ao apoio da nascente questão indígena são os principais fundadores e coordenadores das mais significativas ONGs de caráter civil que se formaram nesse período, como é o caso da Comissão Pró-Índio de São Paulo, do Rio de Janeiro e do Acre, do Centro de Trabalho Indigenista de São Paulo, da Associação Nacional Apoio ao Índio da Bahia, e do Centro Maguta no Rio. 
de prestar assistência em campo aos professores, além das articulações interinstitucionais com a Secretaria de Educação e órgãos afins, os quais deveriam garantir infra-estrutura humana e material para as escolas e a qualidade pedagógica do trabalho educacional sob novos parâmetros.

No Acre e em algumas outras regiões do Brasil, são oferecidos, a partir desse período, de forma contínua, os primeiros Cursos de Formação de Professores Indígenas, professores, na época, ainda denominados monitores bilíngües. Tais projetos se configuravam como uma resposta a lideranças indígenas na época das chamadas "lutas pelos direitos". Esses solicitavam às instituições de apoio que atendessem aos novos tempos com novas formas de serviços educativos dirigidos aos jovens indígenas escolhidos para os papéis de liderança, capacitando-os para atuar na gerência das nascentes cooperativas, na saúde, na educação escolar e, inclusive, na sua luta maior pela conquista e gestão das terras indígenas. "Nós queremos aprender a fazer conta, tirar nossos saldos, não queremos mais ser explorados pelos patrões dos seringais" (Aquino, 1987).

Os projetos de educação indígena desenvolvidos nessa ocasião foram, pois, experiências de caráter bastante autônomo e comunitário, com grande dose de intuição, voluntarismo e mobilização política dos atores, que só gradualmente passaram a se integrar e a se relacionar institucionalmente com os sistemas públicos de ensino, nas esferas federal, estaduais e municipais.

\section{A CIDADANIA E A DIVERSIDADE NO CURRÍCULO}

Importava já nessa ocasião conciliar duas ordens de questões características dos fundamentos políticos dos regimes democráticos que começavam a ser formuladas nos países latino-americanos: a cidadania e a diversidade. Ou seja, buscava-se enfrentar o direito de exercício da cidadania, entendido como participação dos emergentes movimentos sociais indígenas na definição dos rumos de suas sociedades como parte do nacional, no marco do pluralismo cultural e da diversidade.

O reconhecimento desse marco conceitual contemporâneo expressou-se na articulação institucional do projeto com as políticas educacionais do estado e do país. Buscou-se, para isso, encontrar estratégias para a sua inserção na rede de ensino público, preservadas a autonomia e a diversidade das propostas curriculares para as escolas indígenas e a formação de seus professores. A aceitação e construção local do novo paradigma implicavam também um problema: como garantir a transformação da experiência piloto, desenvolvida até ali de forma alternativa às ações oficiais, em uma nova prática de política pública? Ela deveria estar 
fundada nos princípios da cidadania e da diversidade, sem perder de vista a participação política dos atores, ouvidos os princípios do clamor indígena pela "autonomia" e "autodeterminação".

Em 1985, um primeiro convênio é firmado pela CPI/AC com o Estado do Acre, a fim de garantir, a médio prazo, o Projeto de Formação de Professores Indígenas e a continuidade das publicações de materiais didáticos destinados às escolas da floresta, de autoria dos professores indígenas do Acre. Também estavam incluídas as viagens de acompanhamento pedagógico às escolas das aldeias, entendidas como momentos importantes de formação dos professores indígenas, e da própria equipe de docentes e assessores educacionais da CPI/AC, que então também se formava. Participaram desse processo, instituições até o momento desconectadas, conjugando-se esforços das esferas federal e estadual numa parceria ainda nascente: além da CPI/AC e do Estado do Acre, por meio da sua Secretaria de Educação, contou-se também com o apoio federal, via Fundação Nacional do Índio (na época, ainda responsável pelas condução da política nacional de educação indígena). Enquanto isso, preparava-se o estado do Acre, financeira e institucionalmente, para a contratação dos professores indígenas formados pela $\mathrm{CPI} / \mathrm{AC}$ e a inclusão das escolas no sistema estadual do Acre, como categorias diferenciadas e especíicas.

Foram, pois, significativas as marcas inovadoras desse convênio no campo da educação escolar indígena: a aceitação pelo Estado, na esfera estadual e federal, do princípio da autonomia curricular e da descentralização gerencial e técnicopedagógica no que diz respeito a uma parte das políticas públicas educacionais. Os professores indígenas passam a existir como funcionários públicos, direito advindo do conceito da cidadania, sem perderem seu vínculo social de compromisso com suas comunidades, o que lhes dá também o qualificativo de "funcionários da floresta”, expressão original inventada por eles. São ainda formados, não em cursos regulares de magistério oferecidos para a área rural, mas por uma instituição civil, dentro de novos parâmetros curriculares, direito relacionado à pluralidade e à diversidade. Ainda que com o apoio financeiro federal e estadual, passam a ser incentivados a tomar consciência e a reagir aos modelos educativos inadequados, assim como a propor e a desenvolver uma prática pedagógica original e ainda sem precedentes na história indígena regional e nacional. Trabalho que, por sua natureza, foi intitulado, desde o seu primeiro formato institucional, Uma Experiência de Autoria. $\bigcirc$ conceito de "experiência" expressava uma linha de ação de caráter alternativo, processual e local, visando atender a algumas das demandas indígenas por políticas educacionais na região. O conceito de "autoria" ocupava o lugar de 
uma metáfora e expressava uma linha de trabalho filosófico e político: aos professores indígenas, em articulação com a sua comunidade, cabia a responsabilidade das decisões relativas à escola, nos aspectos administrativos e pedagógicos. Buscava-se a vivência responsável, no âmbito educacional, da autonomia e da autodeterminação. Sobretudo, passavam a explicitar e divulgar novos e velhos conhecimentos, selecionados como conteúdos de aprendizagem para si e seus alunos, por meio de suas próprias vozes faladas e escritas, base do novo currículo em construção.

Tornava-se possível e desencadeava-se assim o início de um ainda circunscrito e frágil modelo de política pública. Com base na parceria entre órgãos governamentais e ONGs, juntavam-se as responsabilidades de esferas distintas de poder, como os níveis federal e estadual, dentro dos princípios de uma educação diferente da preconizada pelos modelos de integração e cristianização anteriores. Trata-se de uma educação flexibilizada pelas especificidades e variedades de sociedades indígenas envolvidas e pelo potencial de participação política dos atores. No entanto, devido ao seu caráter inovador, tal projeto não podia contar com referenciais teórico-metodológicos prévios além dos princípios políticos e pedagógicos fornecidos pela Educação Popular.

\section{PARA PENSAR O CURRÍCULO DA FORMAÇÃO DE PROFESSORES INDÍGENAS}

No sentido de suprir a ausência de referenciais anteriores relativos às práticas políticas e pedagógicas para a educação escolar indígena, no que diz respeito aos problemas teóricos, pedagógicos e institucionais na conformação do campo da educação bilíngüe e intercultural, esforços diversos, sob minha coordenação, foram desenvolvidos pela equipe de educação da CPI/AC.

No aspecto teórico, linhas de pesquisa e investigação aplicadas ao campo educacional são criadas e desenvolvidas pela equipe de consultores e assessores da CPI/AC. Como resultado, um número significativo de dissertações de mestrado e teses de doutorado, realizadas em várias universidades brasileiras, dedicavam-se a refletir sobre o contexto em que se desenvolve o projeto educativo da CPI/AC ${ }^{4}$.

4. No total, foram até hoje escritas 13 dissertações de mestrado e 7 teses de doutorado em antropologia, lingüística, geografia, educação e literatura, impulsionadas pelo trabalho da CPI/ AC e de universidades como a Federal Fluminense - UFF -, Federal de Pernambuco - UFP -, Federal do Acre - UFAC -, Federal de Minas Gerais - UFMG -, a de Campinas - Unicamp -, e a de São Paulo - USP -, e que puderam refletir sobre as práticas curriculares desenvolvidas no Acre indígena e subsidiá-las. 
Além disso, várias formas de registro - planejamentos de cursos, relatório de cursos e viagens de assessoria - são elaboradas e difundidas pela equipe de docentes para a própria equipe e para o intercâmbio com outros projetos similares.

No aspecto pedagógico, o currículo de formação dos professores indígenas e de suas escolas é tema de investigação, parte indispensável da formação profissional e de fortalecimento político dos professores indígenas. Estes se dedicam a pensá-lo, ano a ano, nos cursos de formação e nas atividades desenvolvidas nas aldeias, utilizando-se de instrumentos reflexivos produzidos ou concebidos nos cursos, na área de pedagogia e pesquisa.

No que diz respeito à esfera institucional, uma ação permanente foi desencadeada junto ao órgão público que normatiza a questão, o Conselho Estadual de Educação, para a análise e apreciação de nossas propostas curriculares originárias das atividades de pesquisa teórica e de ação pedagógica anteriormente citadas. Buscava-se proceder, permanentemente, à sistematização escrita dos currículos em construção nas escolas indígenas e nos cursos de formação de acordo com um desenho-memória, para lhes dar consistência não só teórica, mas pedagógica e política e regulamentá-los junto aos órgãos de estado.

Como resultado desses três tipos de esforços articulados - o teórico, o pedagógico e o institucional - aprovou-se no Conselho Estadual de Educação do Acre, em 1993, dez anos depois da existência e do desenvolvimento da nossa "experiência de autoria" como ação curricular alternativa, uma proposta diferenciada de currículo para as escolas indígenas inseridas no ensino fundamental. Ela prevê o seu direito de as escolas promoverem o ensino das línguas maternas e os seus próprios processos de aprendizagem, já definidos como direitos pela Constituição Federal, em 1988.

Da mesma forma, a equipe dos assessores, consultores e professores indígenas elaborou entre 1995 e 1996 um documento curricular destinado à formação do magistério indígena de nível médio, sistematizando a ação educativa experimentada no processo de formação de professores desde 1983. Esse documento, mais que planejamento prospectivo, representa a investigação sobre os 15 anos de trabalho e reflete uma prática constituída (e constituinte). Aprovado pelo Conselho Estadual de Educação - CEE - em 19935, conseguiu-se o reconheci-

5. Vale a pena reproduzir aqui parte da análise da relatora do CEE sobre a proposta curricular apresentada: "a proposta é extremamente rica e profundamente fundamentada, existindo coerência entre os elementos que a compõem e desses com os pressupostos teóricos que a sustentam. Somos favoráveis à aprovação da proposta curricular para as escolas indígenas do Estado, ressaltando que a equipe designada pela SEC para fazer seu acompanhamento, deverá fazê-lo como um trabalho em conjunto com o grupo elaborador da referida proposta, sob pena de descaracterizá-la" (Fonseca, 1993). 
mento do currículo de capacitação e formação inicial do grupo de professores indígenas do Acre. Esses, em serviço em suas escolas há mais de uma década, puderam ser titulados como professores bilíngües de nível médio, dentro de uma nova categoria do magistério nacional. Tendo em vista a formação recebida, além desse direito, passaram a ter um plano de carreira para sua profissão, saindo da sua anterior identificação com o professor leigo do meio rural.

O vôo curricular mais ousado da experiência acreana no terreno das políticas públicas ocorreu no âmbito federal no final dos anos 90. Um importante documento curricular nacional - o Referencial Curricular Nacional para as Escolas Indígenas, RCNEI - foi formulado pelo MEC, com a assessoria de um amplo grupo de docentes de projetos e programas de formação de professores indígenas e dos próprios professores indígenas. Entre esses, grande parte da equipe da CPI/AC, tendo ficado a coordenação técnica do documento sob minha responsabilidade. Destinava-se o material a orientar, sob o carimbo do Ministério de Educação, a qualidade na condução de políticas de educação escolar indígena, incentivando a participação política e a busca de consenso entre os diversos setores atuantes no campo.

Os currículos propostos e desenvolvidos, no âmbito regional ou nacional, como nos casos acima referidos, tiveram em comum as condições históricas complexas de parcerias interinstitucionais e os ambientes interculturais de convivência entre as sociedades indígenas participantes. Essa complexidade coloca para nós educadores índios e não índios - algumas questões de difícil resolução que até hoje caracterizam o campo da educação escolar indígena, não só no projeto acreano: como garantir a participação das escolas, de alunos e professores indígenas no sistema nacional de educação, com acesso garantido aos três níveis de estudo, com os benefícios e garantias relacionados à cidadania, sem perder o direito à diferença e à pluralidade? Ou seja, como garantir a legitimação e a legalização pelo poder público de trabalhos educativos diferenciados em sua proposta curricular, mas inseridos, por sua condição interativa e intercultural, no sistema de ensino fundamental? Como atender à demanda dos professores indígenas por um plano de carreira profissional, em modalidade especial da profissão de magistério, que garanta a sua formação inicial e continuada, sua titulação e a adequada remuneração pelo poder público? E, finalmente, como conciliar esses novos processos históricos, educacionais, administrativos com princípios e rotinas dos processos de socialização não escolares, fundamentais para o desenvolvimento humano, ecológico, cultural e político das sociedades indígenas? 


\section{REDEFININDO O CURRÍCULO E AS IDENTIDADES INTERCULTURAIS}

Antes eu pensava que só nós mesmos vivíamos, só nós mesmos,

o povo Kaxinawá.

Tene (in Spyer, Gavazzi, 1992)

Em resumo, pode-se afirmar que os currículos desenvolvidos no contexto dos projetos das ONGs têm influenciado muitas das orientações curriculares oficiais do Ministério da Educação, com suas conseqüências sobre a língua, a cultura e a identidade daqueles a quem se dirigem: professores e alunos indígenas. No entanto, interessa-me aqui também estender tais discussões aos espaços não abarcados pelas políticas oficiais. Para isso, desfoco os currículos da perspectiva institucional e histórica até aqui detalhada, em que priorizei o seu entendimento como documentos de autoria múltipla, campo de confronto de interesses e de estratégias político-institucionais por diferentes grupos sociais. No lugar, passo a abordar a questão curricular na perspectiva dos professores indígenas: ação social significativa, de caráter comunicacional e intercultural, os currículos são processos de construção de significados históricos, no vasto campo das relações de ensino-aprendizagem envolvidas na escola.

Nesses novos contextos históricos aqui relatados, os professores indígenas vêm tentando reagir às condições anteriores impostas pelas escolas das agências que atuam no contato, reforçando as suas vozes agora na qualidade de autores. Concebem a educação não como oportunidade para a dominação e a conquista, e sim para a transformação dos conquistados em conquistadores, sujeitos políticos, usuários ativos que buscam o controle do meio e da mensagem.

Assim são renovados não só os objetivos e conteúdos curriculares, mas, sobretudo, os métodos que orientam os processos de ensino-aprendizagem e o que é selecionado e transformado em conhecimento escolar. Além das mudanças e motivações oferecidas pelos novos "conteúdos culturais", ancorados na tradição e na oralidade, novos meios de comunicação e tecnologia são adquiridos, sobretudo nos cursos de professores indígenas, como as linguagens audiovisuais, as cênicas e as plásticas. A linguagem verbal tem, entretanto, seu lugar cativo e prioritário nos currículos, considerada principal saber e meio de comunicação na escola, em sua dimensão bilíngüe. Busca-se, com entusiasmo, o domínio progressivo das línguas oral e escrita, como transversalidade em todas as áreas de estudo, tendo como meta a ampliação das capacidades de expressão e comunicação nas línguas indígenas, portuguesa, e em outras de interesse comunicativo, como a espanhola e a inglesa. 
conceito de currículo passa a ser explorado como o locus em que se formam e se transformam os sujeitos dos processos escolares e suas múltiplas identidades interculturais. Essas emergem e são constantemente reposicionadas por meio das práticas discursivas elaboradas na interação com os outros, e que se materializam de forma multilíngüe na e pela língua(gem). Elaboradas em contextos educacionais, e considerando-se o grau de prestígio social da escolarização entre os professores em formação, tais práticas curriculares desempenham um papel importante na conscientização de si, definindo e redefinindo "suas" identidades em relação aos diversos "outros".

\section{OS OUTROS, QUEM SOMOS? NÓS, OS PROFESSORES INDÍGENAS}

Volto a recorrer a uma retrospectiva histórica, antes de prosseguir a reflexão sobre os professores indígenas como sujeitos de complexa ação social e comunicativa nos currículos interculturais. $\bigcirc$ objetivo é buscar entender em que medida as condições históricas nas quais esse tipo de projeto foi gerado influenciaram muitas das orientações e metodologias estabelecidas pela equipe da entidade no processo de ação educacional com os professores, assim como provocaram certas contradições e problemas de difícil solução.

Por sua constituição regional, o Projeto de Autoria apresentava, desde o primeiro curso de professores índios em 1983, uma complexidade no tratamento da temática da cidadania e da diversidade: enfrentava-se o desafio de ter como meta o fortalecimento e a valorização do apagado conceito das identidades étnicas em contextos de multilingüismo. Formávamos uma equipe de assessores não índios e um conjunto diversificado de aproximadamente 40 estudantes de uma dezena de etnias regionais, pertencentes a duas famílias lingüísticas, Pano e Aruak, vivenciando variado leque de situações sociolingüísticas com relação à vitalidade e ao deslocamento de suas línguas indígenas em comparação ao português. Tal contingência ajudou a formatar a proposta institucional e política do trabalho, imprimindo-lhe ao mesmo tempo o caráter de uma "experiência" com abrangência de um "programa". A oferta de um serviço social educativo pela entidade não podia, pois, restringir-se a uma só etnia e língua, como era mais comum na época e adequado aos projetos educativos que quisessem aprofundar sua pesquisa lingüístico-cultural ${ }^{6}$.

6. Ainda que tivesse sido fruto de uma relação institucional com uma só etnia, já que a CPI/AC foi solicitada a apoiar inicialmente os Kaxinawá do Rio Jordão a desenvolverem de forma pioneira a luta pela conquista da primeira terra indígena regional, outras etnias do estado e das fronteiras 
Para que o projeto pudesse atuar dentro de seus objetivos, certas opções institucionais se fizeram necessárias na ação educacional com os professores indígenas: desde o primeiro curso, foi atendida aproximadamente uma dezena de sociedades indígenas em quase todos os municípios do estado. Ampliou-se dessa forma para uma abordagem interétnica e intercultural, o escopo mais local e "etnográfico" que poderia ter sido dado numa ação junto a uma só etnia e língua, em sua inevitável especificidade cultural e lingüística.

A condição multilíngüe e pluriétnica da "população-alvo" implicava desenvolvermos procedimentos que permitissem atender tanto à explicitação e ao aprofundamento dessa diversidade - construindo-se pesquisas e estudos que transformassem em currículo cada uma das línguas e culturas - quanto à articulação entre cada professor e à totalidade dos professores presentes, tendo em vista o sentimento de coletividade também como sociedades indígenas do Acre, do Sudoeste do Amazonas e do Brasil. Enfim, articular os conhecimentos de cada sociedade com os conhecimentos entendidos como dos "outros".

Buscaram instrumentos, técnicas e meios de favorecer a reflexão e a identificação das diferenças, no esforço de conceber o coletivo; focar e desfocar, momentaneamente, as identidades étnicas e históricas particulares, ampliar a discussão ao marco global comum, sem perder a conexão com as particularidades contextuais.

No caso, uma identidade indígena regional foi sendo formulada pelos professores como categoria política e profissional, que os inseria num contexto histórico-geográfico comum e, ao mesmo tempo, os diferenciava do restante da população. Concomitantemente, eram ressaltados os aspectos que os identificavam como membros de sociedades indígenas em suas particularidades. Identidades indígenas múltiplas, Kaxinawá, Apurinã, Manchineri, Jaminawa etc., são também parte de uma escala regional e nacional na convivência difícil da cidadania com a diversidade:

Queremos aprender a ler e escrever e tirar nossas contas para não sermos enganados pelo branco no peso e no preço da borracha e das mercadorias. E o índio não tem vergonha de falar a sua própria língua. Eu sou índio Kaxinawá do Rio Jordão. (Siã, in Monte, 1984, p.8)

solicitaram também a participação nos cursos de formação, assim como o apoio ao conjunto de lutas sociais que caracterizaram a ação indigenista naquele período (terra, cooperativa, saúde etc.). 
Ao formularem suas identidades sociais, os professores procuravam centrar o interesse no conhecimento da "própria história", relacionando-a à história de sociedades indígenas de outras regiões do Brasil, e também de outros países, sem que se perdesse a conexão com a história dos "outros outros", tanto próximos como do outro lado do planeta. "Para entender certas coisas que acontecem na aldeia a gente tem de entender certas coisas que acontecem no mundo e vêm de longe" (Prof. Kateyuve, in Monte, 1996, p. 8I).

Como parte dos eixos de interesse do currículo intercultural, diversos objetos de conhecimento, em diversas escalas de tempo e de espaço, foram e são selecionados para estudo pelos estudantes indígenas dos cursos de formação. Há assim a oportunidade de produção de certos significados sociais sobre e para si, pelo conhecimento dos "outros". Tais oportunidades são potencializadas por metodologias apoiadas nas comparações e no confronto de diferenças, numa seqüência de base indutiva, saindo-se do entendimento do "próprio" para o "alheio", conceitos, como vimos, com grande tendência de transformação.

É através da história que a gente pode saber das coisas que se passaram antes com o nosso povo. Não só com nosso povo, mas com outros povos também. Estudando história a gente sabe das notícias de longe, de outros lugares, do Acre, da Amazônia e do Brasil. Sabe das notícias de outros países que nunca viu nem ouviu falar. (Prof. M. Socorro Yawanawá, in Monte, 1996, p. 82)

Normalmente, a seqüência é representada pelos círculos concêntricos, partindo do interior para o exterior, por meio dos nexos e relações que se fazem entre esses centros de interesses, movendo-se do que chamam de "próprio" e "tradicional", para o que é dos "outros": "O currículo deve ser elaborado seguindo os conhecimentos tradicionais da comunidade, sempre associados ao conhecimento de outras culturas de forma integrada" (Professores do Acre, in Brasil, 1998, p. 60).

Por se tratar de educação intercultural, experimentada em contextos indígenas, há séculos confrontadas por dominação e assimetria com os Estados e sociedades nacionais, a ênfase afetiva no que chamam de "próprio" e de "cultura tradicional” dá ao discurso dos professores um forte viés ideológico e, aos procedimentos didáticos, uma indispensável metodologia indutiva: a base e a vértebra dos processos aquisitivos estão assentadas na cultura e na língua própria, de onde devem advir, por nexos históricos e conexões discursivas permanentes, os novos conhecimentos comuns a outras sociedades, apropriados também pela intercomunicação na escola. 
Nós já tivemos aula de história que começou com a história dos portugueses, com a chegada dos brancos no Brasil. Isso é importante. Mas na minha idéia, não devemos começar a estudar a história por aí, porque demora muito a chegar na história dos índios do Acre. Nesse meio, a gente anda por muito canto que não conhece e ouve falar num bocado de gente que nunca nem ouviu antes. Fica arriscado se perder pelo caminho da história e nem saber como chegar no Acre. Para estudar história é melhor sair da aldeia e partir para o mundo. (Prof. Kateyuve, in Monte, 1996, p. 83)

Uma contradição está, pois, instalada nas conceituações e demandas dos professores e outros membros indígenas sobre educação: várias sociedades indígenas, ao longo dos últimos anos, vêm defendendo a educação intercultural para a "manutenção, recuperação e resgate" de suas identidades indígenas diversas e comuns, fundadas em sua cosmovisão e em seus processos de aprendizagem particulares. Ao mesmo tempo, sua formulação intercultural e bilíngüe reflete a vontade de participarem de forma determinada, e autodeterminada, das chamadas sociedades nacionais nas quais sobrevivem à margem e marginalizados como sociedades minoritárias. Para isso, devem manter e aprofundar o nexo histórico com as novas identidades: sociedades indígenas e sociedades específicas: Kaxinawá, Xavante, Krahó, Yanomami, Guarani etc. É necessário, portanto, que possam definir diversos aspectos curriculares e pedagógicos de suas escolas, como parte de definições mais abrangentes de seus projetos históricos como sociedades.

Algumas outras questões dilemáticas estão instaladas nesse tipo de projeto: não existe um corpo único e singular de conhecimentos e procedimentos pedagógicos que possibilitem pensar uma base cultural e cognitiva comum, indígena ou "pan-étnica" (Maher, 1996) para um programa regional e nacional de educação indígena. Do ponto de vista educacional, as sociedades indígenas não comportam uma alternativa única e homogênea, como ocorre com a educação ocidental. Ao contrário, essas sociedades, em sua diversidade, apresentam um ampliado panorama de filosofias, línguas e perspectivas político-históricas. Ao mesmo tempo, encontram pontos de contato entre si, em sua pauta política, no conjunto das lutas pela cidadania e pela diversidade, como macrodireito coletivo e individual (direitos variados que vão desde a propriedade e o usufruto da terra à liberdade de expressão e reprodução cultural). Partilham padrões históricos comuns de colonização e se reúnem para combater os seus efeitos.

Assim, da convivência entre os professores indígenas, explicitando e projetando mutuamente suas identidades específicas e gerais, vem resultando a identificação profissional e social que desloca as fronteiras para limites móveis - desde a 
autodenominação de "nós, os professores índios do Acre", distintos dos demais professores índios brasileiros (e do mundo), até os limites cada vez mais discretos e indivisíveis como na seqüência "nós, os professores Huni Kui ou Kaxinawá", "nós, os professores Asheninka", "nós, os professores Apurinã", e, ainda, a sua diferenciação como comunidade mais local "nós, os professores da comunidade Kaxinawá do Rio Jordão", "nós, os professores Asheninka da aldeia Apitxa”, "nós, os professores Apurinã do Km 45" etc.

\section{ALGUNS POSSÍVEIS CAMINHOS E TEXTOS PARA O CURRÍCULO}

Ao desenvolverem atividades com a língua e a linguagem, os professores indígenas podem construir identidades multifacetadas como discurso pedagógico, nas situações didáticas propiciadas em sua formação e na de seus alunos:

Nesse ano, pretendo pesquisar na minha comunidade Apurinã do km 45 matemática, história, geografia Apurinã, língua Apurinã... na matemática, quero pesquisar onde e em qual momento que a matemática é usada no conhecimento Apurinã... na geografia Apurinã, quero entender sobre a chuva, o trovão e o arco-íris. Na história, quero pesquisar os seguintes conteúdos: o surgimento do Tsorá, os mitos e concluir a pesquisa sobre o passado do meu povo... Na língua, quero entender os verbos, pronomes e aprofundar mais meu conhecimento da língua. Todas as disciplinas da cultura Apurinã serão pesquisadas através dos velhos que sabem contar. (Prof. Geraldo Aiwa Apurinã, in Brasil, 1998, p. 81)

Com esses procedimentos de ensino e pesquisa, os professores estimulam a construção do conhecimento escolar e a diversificação das aprendizagens. Em forma de produtos e textualidades de vários gêneros, sempre expressados pelas línguas, em sua modalidade oral e escrita, eles apresentam formulações sobre essas múltiplas e conflituadas identidades.

Eu estou trabalhando com o português, porque agora a gente tem mais contato com o branco para fazer negociação de compra e venda. Também quero formar mais alunos para escreverem pequenos textos em português e quero que leiam qualquer tipo de escrita: bilhete, rótulos, cartas, jornais... quero que consigam dialogar com amigos e não-amigos e resolvam qualquer problema na cidade. (Shere, in Brasil, 1998, p. 121)

Distintos, como unidades coesas e particulares - Kaxinawá, Katukina, Yawanawá etc. -, os professores devem, ao mesmo tempo, reposicionar-se no coletivo, pela construção de um sentido (e de um sentimento) de ser parte do 
conjunto maior, como sociedades indígenas, seja afirmativamente em relação a si mesmos, seja no confronto e na comparação com o outro, quase sempre metaforizado como o "branco":

Eu sinto que sou índio porque meu pai é índio, minha mãe é índia, minha avó é índia, e todos meus parentes são índios... sinto que sou índio porque não tenho cara de branco, meu corpo é diferente, meu jeito de caminhar é diferente... (Professores indígenas, in Spyer, Gavazzi, 1992, p. 46)

De grande importância na proposta curricular para sua formação como professores, estão os materiais de lecto-escritura, resultantes das suas atividades de pesquisa de campo, publicados na forma de livros com tiragem reduzida para uso nas escolas. Esses materiais são textos e desenhos produzidos ao longo das variadas atividades de pesquisa organizadas por professores indígenas em suas terras, e/ou nos cursos intensivos anuais. Entre esses, alguns têm forte marca distintiva, pois normalmente são registrados pelos professores em língua materna indígena, como Shenipabu miyui [História dos antigos] (Mana e Monte, 2000), Nuku mimawa [Nossos cantos] (Mana e lbã, 1995), em que a totalidade do material ou grande parte dele está escrita em Kaxinawá. Nas apresentações desses livros, e somente aí, os autores descrevem em língua portuguesa sua história e função:

Este livro de música Kaxinawá, Nuku Mimawa, foi trabalho realizado por alguns professores Kaxinawá interessados em registrar sua cultura no momento em que a língua Kaxinawá passou a ser dominada pela escrita. Eu, Joaquim Mana e Isaías Ibã fizemos algumas gravações com os velhos... Nosso objetivo é que essas músicas façam parte da disciplina de línguas das escolas Kaxinawá... (Mana, in Mana, Ibã, 1995, p. I)

Os exemplos acima são fruto das atividades curriculares de professores Kaxinawá relacionadas a sua experiência cultural, histórica e religiosa específica, própria da auto-identificação como sociedade particular. Professores de outras etnias (como os professores Katukina, Manchineri, Yawanawá), marcando suas fronteiras, não só produziram inúmeras cartilhas de leitura e alfabetização, matemática e geografia em suas próprias línguas, como também reuniram narrativas míticas e cantos rituais.

Outros materiais, complementares aos citados, como o livro História indígena (Piedrafita, Ochoa, 1997), ou Estória de hoje e de antigamente dos índios do Acre e sudoeste do Amazonas (Monte, 1984), também são exemplos de sua auto-representação social como sociedades indígenas, ou sociedades indígenas do 
Acre e do sudoeste do Amazonas. Neles, os professores explicitam um discurso de forte conotação política. Por meio de textos e imagens da memória histórica do conjunto de professores do projeto, apontam sua pertinência para um marco comum, determinado contextualmente pela forma de ocupação territorial e socioeconômica das frentes de expansão neste século na Amazônia brasileira.

Para entender o que ainda hoje tem da herança de nossos antepassados, vamos caminhar por vários tempos: tempo das malocas, das correrias, do cativeiro, dos direitos e do governo dos índios. Viajando nesses tempos, vamos pensar nas diferentes formas de organização de nosso povo. Veremos o que ficou, o que aprendemos de novo, o que foi deixado para trás e como foram se transformando nossas formas de viver... (Ixã, in Brasil, 1998, p. 15)

Expressam e reinterpretam, por meio desses textos, as histórias particulares das suas etnias, elaborando estudos das próprias histórias como as seguintes: "Assim os Katukina começamos a lutar pela nossa terra", "Nós Apurinã estamos nos organizando assim", "História Manchineri antes do contato", "Porque nosso povo Jaminawa vive todo espalhado". Nesses textos, a pertinência a vários específicos reúne-os entre si, e ao mesmo tempo difere-os de todos os demais:

A história nos ajuda a entender o presente. Conhecendo nosso presente podemos pensar no futuro. E para entender o presente é importante conhecer e aprender com as tradições e com a história de tudo que nosso povo Kaxarari, Kaxinawá, Apurinã passou. Desde o começo do mundo até os dias de hoje. (Idem, p. 198)

Outros materiais de autoria dos professores nas disciplinas de Geografia e Literatura compõem e ilustram esse currículo em movimento pendular como o Atlas geográfico indígena do Acre (Spyer, Gavazzi, 1998). Nele, o foco da lente constrói a narração em viagem, por espaços que deslocam o olhar da aldeia ao "outro lugar" - o Acre, o Brasil, o mundo, e o universo:

Viajei do Acre num barco. Era de casca de cumaru. Fui conhecer outros estados.

Do continente da América do Sul. (Prof. Muru Kaxinawá, in Spyer, Gavazzi, 1998) $[\ldots]$

Viajando como satélite, no mais alto do alto, vejo o Acre com uma cor atraente: verde amarelo.... (Prof. Llullu Manchineri, in Spyer, Gavazzi, 1998)

Outro resultado das atividades de pesquisa com enfoque intercultural no currículo é o material Antologia da floresta: literatura selecionada e ilustrada pelos professores índios do Acre (Mattos, 1997), produto do longo processo de sua formação em língua portuguesa e literatura. Para elaborá-lo, os professores fize- 
ram a leitura crítica e a seleção de textos considerados literários, provenientes da tradição oral e escrita de diversas culturas brasileiras. Incluiu-se e demarcou-se um capítulo de poesia e prosa de autores indígenas contemporâneos, separado do capítulo de "autores não índios", representado por Gonçalves Dias, Mário de Andrade, Manuel Bandeira e Manuel de Barros, selecionados por sua lente grande-angular. Apreciados por esses professores como os mais "divertidos, alegres e prazerosos", tais textos foram escolhidos e assim consagrados pelo valor literário, passando a integrar o repertório de textos do currículo de suas escolas.

Esses textos da nossa primeira antologia foram escolhidos depois de muitas leituras, anotações e votos feitos por nós professores de cada região. Foi um trabalho coletivo com todos os professores que estavam presentes: ler 74 textos e fazer a seleção dos mais bonitos e engraçados... (Mattos, 1997, p. 1)

\section{O PÊNDULO DAS IDENTIDADES NO MOVIMENTO CURRICULAR}

Temos uma educação diferente e uma escola diferenciada. E só iremos respeitar o outro povo, conhecendo o diferente.

Mana (in Spyer, Gavazzi, 1992)

O conceito de identidade étnica e linguagem está intrinsecamente relacionado ao movimento de adscrição e exclusão (Maher, 1996, 1998; Kleiman, 1998) no exercício permanente de auto-representação do próprio e do alheio. Tais movimentos implicam a construção, conservação e modificação de um limite nas relações sociais entre os que são "membros e estranhos", nas fronteiras móveis da identificação social. "Somos iguais e diferentes. Diferentes na língua, jeito e costume. Igual no corpo, na inteligência, no respeito. Somos todos iguais: índios, negros e brancos..." (Spyer, Gavazzi, 1992).

Usando a linguagem - e as línguas - em situações didáticas promovidas pela experiência curricular, os professores indígenas podem construir e projetar suas identidades sociais. Em sua comunicação intercultural, por meio de atividades expressivas e comunicativas, usam, de forma alternada ou exclusiva, uma ou mais línguas selecionadas, dependendo da momentânea identificação simbólica e comunicativa com determinadas comunidades de falantes: uma identidade indígena "genérica", regional e/ou nacional, com função política estratégica, normalmente tem sido explicitada na língua portuguesa, em contraste com a potencial escolha e uso da língua indígena, para se referir aos conhecimentos "próprios" de cada etnia ou de cada comunidade indígena em particular. 
Materiais diversos desenhados, esculpidos, narrados oralmente, dramatizados e escritos podem ser as expressões e recriações de uma identidade diferencial de limites marcados, própria à vivência da interculturalidade e do multilingüismo. Ao atuarem como alunos dos cursos e professores das escolas nas aldeias, os professores vêm elaborando um conjunto de textos diversificados, configurandose uma produção de sua "autoria" nas línguas indígenas e na língua portuguesa. Também, como já relatado, um conjunto diversificado de obras não apoiadas estritamente na palavra vem ganhando função pedagógica no currículo da escola indígena. Essas obras passam a compor não só o material de apoio ao currículo das escolas ao longo do ano, como também são procedimentos importantes para formar professores do ponto de vista pedagógico e torná-los pesquisadores de novos conteúdos curriculares. Entre essas obras culturais e educacionais, destacam-se os vídeos etnográficos, concebidos e dirigidos por eles. Normalmente falados em língua indígena, constituem novos meios para suas atividades de pesquisa sobre a "cultura própria", complementando alguns dos livros didáticos já citados anteriormente, elaborados também em língua indígena. Outras obras importantes em língua portuguesa que integram esse currículo intercultural são as práticas de pesquisa dos professores durante cursos e nas atividades a distância, como os "diários de classe", os "projetos político-pedagógicos" etc. ${ }^{7}$, cada vez mais adotados em projetos de educação indígena no país como instrumento reflexivo sobre e para a melhoria da sua formação profissional.

A convivência permanente entre variadas construções de identidades, em línguas, suportes e discursos diversos, implica "a conservação de um limite. Os aspectos culturais que assinalam este limite podem mudar" (Barth, apud Maher, 1996), e as mudanças demarcam os diferentes conjuntos de saberes advindos de diferentes escalas de representação social da identidade e da diferença. As formas e os conteúdos lingüísticos e culturais que se modificam vão implicando fronteiras de identificação, representadas por uma linha contínua, e não necessariamente

7. Os diários de classe são documentos curriculares escritos durante o ano letivo pelos professores do projeto do Acre, estimulados didaticamente pelos docentes nas diversas áreas de estudo desde seus primeiros cursos. Neles, registram e refletem sobre o currículo em desenvolvimento nas escolas indígenas onde são professores. Mais recentemente, os professores passaram a ser autores de novos textos curriculares, os projetos político-pedagógicos, elaborados individualmente e/ou por etnia, ao longo dos cursos de pedagogia, e aprimorados durante o ano nas aldeias, com a assessoria da equipe de educadores da entidade, nas suas viagens de acompanhamento de campo. Esses documentos devem ser fundamentais nos próximos anos para a regularização final das propostas curriculares das escolas indígenas brasileiras, tomadas em suas particularidades e especificidades étnico-lingüísticas, junto aos conselhos estaduais de educação. 
hierarquizada, de corpus de conhecimentos, que costumam ser agrupados sob os conceitos de "conhecimento universal, nacional, local".

Os currículos escolares indígenas ganham assim um caráter de permanente movimento ondular entre aqueles conjuntos de conhecimentos representados como étnicos e locais, demarcadas as fronteiras entre as etnias e as línguas que falam, e a chamada "base universal do conhecimento escolar", entendidas ambas como ponto de partida e chegada para a desejada cidadania com diversidade. Esses conhecimentos lingüísticos e culturais múltiplos, selecionados pelos professores de diferentes etnias nesse processo de ensino-aprendizagem mútuo, passam a pertencer aos currículos escolares e a expressar e potencializar diferentes tipos de identidades sociais.

Como já afirmado, a construção de significados sobre si mesmo e os outros, nos nexos que se estabelecem por meio do currículo, faz deste o lugar e o momento especial de autodefinição e redefinição das identidades, em situação de multilingüismo e interculturalidade.

\section{REFERÊNCIAS BIBLIOGRÁFICAS}

AQUINO, T. Breve História do Contato. In: CABRAL, S., MONTE, N., MONSERRAT, R. Por uma educação indígena diferenciada. Brasília: Pró-Memória INC, 1987.

BRASIL. Ministério da Educação e do Desporto. Diretrizes nacionais para a educação escolar indígena. Brasilia, 1993.

. Documento técnico preliminar para a formação de professores. Brasília, 1999.

- Referencial curricular nacional para as escolas indigenas. Brasilia, 1998.

FONSECA, M. Parecer 17//93 do Conselho Estadual de Educação do Acre. Rio Branco, 1993.

KLEIMAN, A. A Construção de identidades em sala de aula; um enfoque Interacional. In: SIGNORINI, I. (org.). Linguagem e identidade. Campinas: Mercado de Letras, Fapesp, 1998, p. 267-302.

MAHER, T. M. Sendo índio em português. In: SIGNORINI, I. (org.). Linguagem e identidade. Campinas: Mercado de Letras, Fapesp, 1998, p. 115-138.

. Ser professor sendo índio: questões de língua (gem) e identidade. Tese (dout.). Campinas, Unicamp, 1996.

MANA, J., IBÃ, I. (orgs.). Nuku mimawa. Rio Branco: Comissão Pró-Índio do Acre, 1995. 
MANA, J., MONTE, N. (orgs.). Shenipabu miyui. 2. ed. Belo Horizonte: UFMG, 2000.

MATTOS, C. (org.). Antologia da floresta: literatura selecionada e ilustrada pelos professores índios do Acre. Rio de Janeiro: Multiletra, 1997.

MONTE, N. Escolas da floresta: entre o passado oral e o presente letrado. Rio de Janeiro: Multiletra, 1996.

. Linguagem no contexto escolar indígena: o caso do Acre. Cadernos ESE, n. I, p. 35-4I, nov. 1993. [Leitura e Alfabetização]

MONTE, N. (org.). Estórias de hoje e antigamente dos índios do Acre e do sudoeste do Amazonas, Comissão Pró-Índio do Acre, 1984.

- (org.) Proposta curricular para a formação dos professores indígenas do Acre e sudoeste do Amazonas. Rio Branco: Comissão Pró-Índio do Acre, 1996.

MONTE, N. et al. (org). Proposta curricular bilíngüe intercultural. Rio Branco: Comissão Pró-Índio do Acre, 1993.

. Proposta de magistério indígena bilíngüe intercultural. Rio Branco: Comissão Pró-Índio do Acre, 1996.

MUNOZ, H. Los objetivos políticos y socioeconomicos de la educación intercultural bilingüe y los cambios que se necesitan en el currículo, en la enseñanza y en las escuelas indígenas. Revista Iberoamericana de Educación, Madri, n. 7, p. 31-50,1998. [Educación, Lenguas, Cultura]

PIEDRAFITA, M., OCHOA, M. (orgs.). História indígena. Rio Branco: Comissão Pró-Índio do Acre, 1997.

SPYER, M., GAVAZZI, R. (orgs.). Atlas geográfico indígena do Acre. 2. ed. Rio Branco: Comissão Pró-Índio do Acre; Brasília: SEF/MEC, 1998.

. Geografia indígena. Rio Branco: Comissão Pró-Índio do Acre, 1992. 